\title{
Comparison Results of Automated Auditory Brainstem Response and Brainstem Evoked Response Audiometry for Hearing Loss Detection in High-risk Infants
}

\author{
Endang Susanti Warasanti, Nyilo Purnami*, Soeprijadi Soeprijadi \\ Department of Otorhinolaryngology, Head and Neck Surgery, Faculty of Medicine, Universitas Airlangga, Dr. Soetomo Teaching \\ Hospital, Surabaya 60131, Indonesia
}

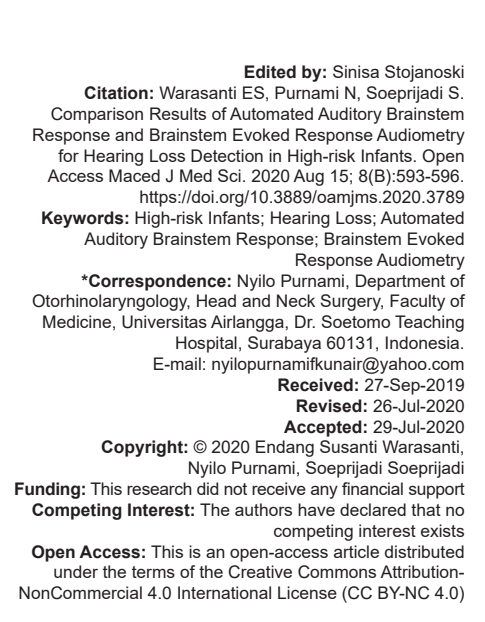

\begin{abstract}
BACKGROUND: Brainstem evoked response audiometry (BERA) is not widely used for hearing screening because it is considered less practical; however, it is often used for diagnostics. Since the founding of automated auditory brainstem response (AABR), it often uses because it is more practical, has a high sensitivity and specificity in early detection of hearing loss $(\mathrm{HL})$ in high-risk infants
\end{abstract}

AIM: The objective of the study was to determine the differences results of AABR and BERA for HL detection in highrisk infants at neonatal intensive care unit (NICU).

METHODS: The study was conducted from November 2014 to September 2015 with consecutive sampling. The subjects were high-risk infants treated in the NICU room of the Neonatology Division at Dr. Soetomo General Hospital Surabaya and examined using AABR or BERA to determine the existence of HL.

RESULTS: BERA results obtained normal (negative) as many as 28 ears (73.68\%) and not normal (positive) as many as 10 ears $(26.32 \%)$. AABR results obtained pass (negative) as many as 23 ears $(60.53 \%)$ and refer (positive) as many as 15 ears (39.47\%). Detection of $\mathrm{HL}$ in high-risk infants in NICU with AABR obtained $40 \%$ of sensitivity and $60.71 \%$ of specificity, $26.67 \%$ of positive prediction (NPP), $73.91 \%$ of negative predictive value (NPN), $55.26 \%$ of accuracy, $39.29 \%$ of false positive error rate, and $60 \%$ of false negative error rate. The comparative test of Wilcoxon signed-rank between the results of AABR and BER obtained $p=0.236$

CONCLUSIONS: There was no difference between AABR and BERA results for HL detection in high-risk infants at NICU.

\section{Introduction}

Early detection of hearing loss $(\mathrm{HL})$ in newborns and infants by newborn hearing screening is necessary for early treatment [1]. The best method to assess the threshold of a hearing was the brainstem evoked response audiometry (BERA). BERA is not widely used for hearing screening because it is considered less practical; however, it is often used for diagnostics. Since the founding of a second-generation BERA tool called automated auditory brainstem response (AABR), this tool is often used for hearing screening programs [2].

$A A B R$ is automatic BERA which can be done quickly and does not require analysis of evoked potential waves. The results are very easy to read because it is only based on pass or refer criteria. Several studies have shown that AABR has been widely used for hearing screening due to its advantages that are more practical, have high sensitivity and specificity in early detection of $\mathrm{HL}$ in high-risk infants. In Germany, AABR has a sensitivity of $98 \%$ and a specificity of $96 \%$. In Italy reported, $378(97.4 \%)$ of 388 ears examined showed an agreement using two techniques of $\mathrm{AABR}$ and BERA, whereas 10 ears $(2.6 \%)$ showed no agreement using two techniques of $A A B R$ and BERA. The result of an interobserver agreement between $A A B R$ and BERA results was very good (kappa $=0.92 \pm 0.02$ S.E., $p=0.0001$ ) and it had $100 \%$ of sensitivity and $96.8 \%$ of specificity [3].

High-risk infants underwent treatment at neonatal intensive care unit (NICU) were at high risk of $\mathrm{HL}$. Abnormalities can cause $\mathrm{HL}$ in newborns, that is, asphyxia, sepsis, hyperbilirubinemia, low birth weight (LBW), and premature [4], [5], [6], [7]. High-risk infants who have hypoxia and ischemia in the tissues resulting in apoptosis that causes irreversible damage to the cochlea and damage to auditory nerve fibers, thus the auditory signal cannot be passed to the brainstem [8].

Sepsis in high-risk infants will be accompanied by systemic toxemia. The infection gets into the bloodstream, stria vascularis, endolymph, and perilymph; then it causes hemagglutination and hypercoagulation. Cochlear blood flow decreases that damage the cochlea and central nervous system resulting in HL [9]. High-risk 
infants with LBW and premature birth often experience neurodevelopmental complications and congenital abnormalities. Serum bilirubin levels of $>17 \mathrm{mg} / \mathrm{dL}$ in infant blood cause in damage to the cochlea, and auditory nerve fibers due to bilirubin toxin, thus the auditory signal to the brainstem is disrupted [10]. Research on the comparison between AABR and BERA has rarely reported abroad. Thus, we aimed to obtain the difference of $A A B R$ and BERA for $\mathrm{HL}$ detection in high-risk infants at NICU of Dr. Soetomo General Hospital Surabaya.

\section{Methods}

This was an observational analytic study that used a cross-sectional approach. The sampling used was consecutive sampling until the minimum size fulfilled. Inclusion criteria were high-risk infants aged 0-3 months who suffer from asphyxia, sepsis, LBW, premature, and hyperbilirubinemia, the baby was stable and transportable, the patient's parents were willing to participate and signed the informed consent. The study protocol was approved by Dr. Soetomo General Hospital Surabaya.

Several tools used for ear examination were headlamps, cotton wool, cotton, and otoscope. AABR: MB11 or BERA Phone was made by Maico, Germany in 2011. BERA tool: Interacoustics Assens DK-5610 was made in Denmark, 2010. BERA was performed by a special officer from a limited liability company (PT) KASOEM Hearing on a schedule of inspection. The results of $A A B R$ and $B E R A$ were read by a specialist doctor of otorhinolaryngology-head and neck surgery and recorded in the data collection sheet; then the data were processed statistically.

The data were processed descriptively using a diagnostic test such as the calculation of sensitivity, specificity, positive predictive value, and negative predictive value; then it was followed by Wilcoxon signed-rank comparative test.

\section{Results}

Nineteen high-risk infants who fulfilled the inclusion criteria were enrolled in this study. The study was conducted in Neurotology Division of Dr. Soetomo General Hospital Surabaya from November 2015 to September 2015. Each subject underwent two examinations of $A A B R$ and BERA on the right and left ear. The basic data of the subjects were age distribution, gender distribution, high-risk factors, AABR results, BERA results, and $H L$ threshold from the BERA results.
Table 1: Age distribution

\begin{tabular}{lll}
\hline Age (month) & Amount & Percentage (\%) \\
\hline $0-1$ month & 13 & 68.42 \\
$1-2$ months & 5 & 26.31 \\
$2-3$ months & 1 & 5.27 \\
Total & 19 & 100 \\
\hline
\end{tabular}

Table 1 showed that the most age group of high-risk infants was 0-1 month's as many as 13 infants $(68.42 \%)$, whereas five infants in the age group of $1-2$ months $(26.31 \%)$ and one baby in the age group of 2-3 months $(5.27 \%)$. The youngest was $<1$ month (9 days) and the oldest was $<3$ months ( 86 days) with mean age of 26.74 (21.07).

Table 2: Sex distribution

\begin{tabular}{lll}
\hline Sex & Amount & Percentage \\
\hline Male & 10 & 52.63 \\
Female & 9 & 47.37 \\
Total & 19 & 100 \\
\hline
\end{tabular}

Table 2 showed 10 male infants $(52.63 \%)$ and 9 female infants $(47.37 \%)$. The ratio of male to female was 1.1:1.

Table 3: High-risk factors distribution

\begin{tabular}{lll}
\hline Risk factors & Amount & Percentage \\
\hline Asphyxia & 13 & 68.42 \\
Sepsis & 0 & 0 \\
Low birth weight & 15 & 78.95 \\
Premature & 12 & 63.16 \\
Hyperbilirubinemia & 11 & 57.89 \\
\hline
\end{tabular}

We found that the most risk factor was LBW of 15 infants (78.95\%), asphyxia of 13 infants $(68.42 \%)$, premature of 12 infants $(63.16 \%)$. and hyperbilirubinemia of 11 infants (57.89\%; Table 3 ).

Table 4: Automated auditory brainstem response results

\begin{tabular}{lll}
\hline Automated auditory brainstem response & Amount & Percentage \\
\hline Pass (negative) & 23 & 60.53 \\
Refer (positive) & 15 & 39.47 \\
Total & 38 & 100 \\
\hline
\end{tabular}

Table 4 showed that the AABR results of pass (negative) were 23 infant ears $(60.53 \%)$ and refer (positive) were 15 infant ears (39.47\%). Distribution of subjects based on the BERA results could be seen in Table 5. BERA obtained normal (negative) results of 28 infants $(73.68 \%)$ and abnormal (positive) results of 10 infants $(26.32 \%)$.

Table 5: Brainstem evoked response audiometry results

\begin{tabular}{lll}
\hline Brainstem evoked response audiometry & Amount & Percentage \\
\hline Normal (negative) & 28 & 73.68 \\
Abnormal (positive) & 10 & 26.32 \\
Total & 38 & 100 \\
\hline
\end{tabular}

The distribution of the subjects based on the threshold degree of the BERA results was shown in Table 6.

Table 6: Threshold degree of auditory based on brainstem evoked response audiometry results

\begin{tabular}{llll}
\hline Threshold degree & Amount & Percentage & Description \\
\hline $0-25 \mathrm{~dB}$ & 28 & 73.68 & Normal \\
$26-40 \mathrm{~dB}$ & 10 & 26.32 & Mild hearing loss \\
$41-60 \mathrm{~dB}$ & 0 & & Moderate hearing loss \\
$61-90 \mathrm{~dB}$ & 0 & & Severe hearing loss \\
$>90 \mathrm{~dB}$ & 0 & 100 & Profound hearing loss \\
Total & 38 & & \\
\hline
\end{tabular}

The table obtained a normal threshold level of 28 infants $(73.68 \%)$ at $0-25 \mathrm{~dB}$ or a $\mathrm{V}$ wave was 
detected at $30 \mathrm{~dB}$ and a minor HL of 10 infants (26.32\%) at $26-40 \mathrm{~dB}$ or $V$ wave was detected at $40-50 \mathrm{~dB}$.

\section{Discussion}

Table 1 showed the age of 19 high-risk babies. Auditory development in humans was closely related to the brain development. Neurons in the cortex undergo a maturation process in the first 3 years of life and a rapid brain development occurs in the first 12 months of life. The critical period for the development of hearing and speech systems begins in the first 6 months of life and it continues to grow until the age of 2 years. In Italy against 206 high-risk infants treated at NICU that used AABR AccuScreen PRO-GN Otometrics/Madsen Electronics/Copenhagen Denmark and BERA Galileo NT evoked response system (EBNeuro/Florence, Italy). One hundred and sixty-one infants aged 1 month (78.16\%), 12 infants aged 2 months $(5.83 \%)$, and 33 babies aged 3 months (16.02\%) [11].

Table 2 showed that 10 male infants $(52.63 \%)$ and 9 female infants $(47.37 \%)$ with the ratio of male to female were 1.1:1. There were differences of opinion between male and female. Several studies reported no gender differences in newborns. Male infants were more likely to experience brain maturation disorders, developmental disorders of brain white matter, and neural dysfunction; however, there was no mechanism that suggested which sex was susceptible to HL [12]. This study was in accordance to a study conducted by Cebulla and Shehata-Dieler in Germany of 6866 newborns, they found 3604 male infants (52.5\%) and 3262 female infants (47.5\%) [13].

High-risk infants with LBW or premature were at high risk of suffering from SNHL HL due to the immaturity of the anatomy and physiology of the auditory organs. LBW in a study conducted by Dewi and Agustin (2011) against 286 newborns showed that the highest risk factors were LBW of 146 infants $(51.1 \%)$, premature of 39 infants $(13.6 \%)$, asphyxia as many as 38 infants (13.3\%), and hyperbilirubinemia of 25 infants $(8.7 \%)$. The difference in this study was seen from the number of risk factors of affected infants.

Table 4 showed that the AABR with MB11 BERAphone on 38 high-risk infants ears resulted in 23 passes $(60.53 \%)$ and 15 refers $(39.47 \%)$. This study was in accordance with a study in Italy by Melagrana et al. with AABR MB11 BERAphone against 388 ears from 201 high-risk infants treated at NICU, they obtained pass results of 303 ears $(78.09 \%)$ and refer as many as 85 ears $(21.91 \%$ ) [3]. The AABR device determined the presence or absence of a BERA wave using the scoring method without the need for visual inspection of operator skills. The data collected were processed by an algorithm to verify the statistic results (pass or refer). The AABR tool determined the presence of BERA waves by verifying the presence of the response at the low stimulus click level (e.g.,: $35 \mathrm{dBnHL}$ ). It examined whether the BERA signal was measured for the noise ratio beyond the defined criterion [12]. AABR waves could be recorded in premature infants at 34 weeks pregnancy [2].

Table 5 showed a normal BERR result of 28 infants $(73.68 \%)$ and abnormal results of 10 infants $(26.32 \%)$. This study was in accordance with a research in Italy by Melagrana et al. using BERA Mercury Epic Audiological system software against 388 ears from 201 high-risk infants treated at NICU that obtained normal results of 313 ears $(80.67 \%)$ and abnormal of 75 ears (19.33\%) [3]. In Canada BERA Amplaid MK-15 was used to 120 highrisk infant ears from 260 infants at NICU obtained normal results of 80 ears $(66.67 \%)$ and abnormal of 40 ears $(3.33 \%)$ [14]. Nonpathological factors that might affect the outcome of BERA were age, gender, body temperature, general circumstances, and the influence of drugs. There was an elongation of BERA wave latency values in newborn infants aged up to 28 days (neonates) compared to adults. Therefore, the BERA results in newborns have a characteristic interval between extended waves. BERA wave could be recorded in premature infants at 25 weeks pregnancy with an average of 27-30 weeks pregnancy [12]. The premature infants in this study had an average pregnancy age of 28-35 weeks.

Table 6 showed the result of $\mathrm{HL}$ threshold from normal BERA examination result of 28 infant ear $(73.68 \%)$ at $0-20 \mathrm{~dB}$ or $\mathrm{V}$ wave was detected at 30 $\mathrm{dB}$. There was mild $\mathrm{HL}$ of 10 infant ears $(26.32 \%)$ at 26-40 dB or $V$ wave was detected at 40-50 dB. This study was in accordance with a research conducted by Chen et al., in Taiwan that obtained 36 normal ears $(47.36 \%)$ and $V$ wave was detected at $35 \mathrm{~dB}$. Then, mild HL of 22 ears (28.94\%) was obtained and $\mathrm{V}$ wave was detected at $45 \mathrm{~dB}$. The moderate $\mathrm{HL}$ was obtained in 18 ears $(23.68 \%)$ and $V$ wave was detected at $60 \mathrm{~dB}$ of 76 infant ears aged 3-4 months [14].

The result of statistical calculation in this research using Wilcoxon signed-rank comparative test obtained $p=0.236$. It could be concluded that there was no significant difference between AABR and BERA with sensitivity of $40 \%$ and specificity of $60.71 \%$. It showed that AABR could be used as a BERA alternative in early detection of $\mathrm{HL}$ in high-risk infants. In Italy, 378 (97.4\%) of 388 ears showed an agreement using two techniques of $A A B R$ and BERA, while there was no agreement using two techniques of AABR and BERA in 10 ears $(2.6 \%)$ [3]. The result of interobserver agreement between $A A B R$ and BERA was very good (kappa = $0.92 \pm 0.02$ S.E., $p=0.0001$ ) with $100 \%$ sensitivity and $96.8 \%$ specificity. 


\section{Conclusion}

Detection of $\mathrm{HL}$ in high-risk infants in NICU using AABR obtained $40 \%$ sensitivity and $60.71 \%$ specificity. There was no difference between the results of $A A B R$ and BERA for HL detection in high-risk infants in the NICU.

\section{References}

1. Jakubíková J, Kabátová Z, Pavlovčinová G, Profant M. Newborn hearing screening and strategy for early detection of hearing loss in infants. Int J Pediatr Otorhinolaryngol. 2009;73(4):60712. https://doi.org/10.1016/j.ijporl.2008.12.006 PMid:19185924

2. Van Dommelen $P$, van Straaten HL, Verkerk PH, Group DNNHSW. Ten-year quality assurance of the nationwide hearing screening programme in Dutch neonatal intensive care units. Acta Paediatr. 2011;100(8):1097-103. https://doi. org/10.1111/j.1651-2227.2011.02230.x

3. Melagrana A, Casale S, Calevo MG, Tarantino V. MB11 BERAphone and auditory brainstem response in newborns at audiologic risk: Comparison of results. Int $\mathrm{J}$ Pediatr Otorhinolaryngol. 2007;71(8):1175-80. https://doi.org/10.1016/j. ijporl.2007.04.011

PMid:17532479

4. Meyer C, Witte J, Hildmann A, Hennecke KH, Schunck KU, Maul $\mathrm{K}$, et al. Neonatal screening for hearing disorders in infants at risk: Incidence, risk factors, and follow-up. Pediatrics. 1999;104(4):900-4. https://doi.org/10.1542/peds.104.4.900 PMid:10506232

5. Sano M, Kaga K, Kitazumi E, Kodama K. Sensorineura hearing loss in patients with cerebral palsy after asphyxia and hyperbilirubinemia. Int $\mathrm{J}$ Pediatr Otorhinolaryngol. 2005;69(9):1211-7. https://doi.org/10.1016/j.ijporl.2005.03.014 PMid: 15908018

6. Cristobal R, Oghalai JS. Hearing loss in children with very low birth weight: Current review of epidemiology and pathophysiology. Arch Dis Childhood Fetal Neonatal Ed. 2008;93(6):F462-8. https://doi.org/10.1136/adc.2007.124214 PMid:18941031

7. Wroblewska-Seniuk K, Greczka G, Dabrowski P, SzyfterHarris J, Mazela J. Hearing impairment in premature newbornsanalysis based on the national hearing screening database in Poland. PLoS One. 2017;12(9):e0184359. https://doi. org/10.1371/journal.pone.0184359

PMid:28910311

8. Sarosa GI, Putranti AH, Setyarini TK. Pengaruh asfiksia neonatal terhadap gangguan pendengaran. Sari Pediatr. 2016;13(1):513. https://doi.org/10.14238/sp13.1.2011.5-13

9. Smith RJH, Zimmerman B, Connolly PK, Jerger SW, Yelich A Screening audiometry using the high-risk register in a level III nursery. Arch Otolaryngol Neck Surg. 1992;118(12):1306-11. https://doi.org/10.1001/archotol.1992.01880120032006 PMid:1449689

10. Amin SB, Ahlfors C, Orlando MS, Dalzell LE, Merle KS, Guillet R. Bilirubin and serial auditory brainstem responses in premature infants. Pediatrics. 2001;107(4):664-70. https://doi.org/10.1542/ peds.107.4.664

PMid:11335741

11. Suppiej A, Rizzardi E, Zanardo V, Franzoi M, Ermani M, Orzan E. Reliability of hearing screening in high-risk neonates: Comparative study of otoacoustic emission, automated and conventional auditory brainstem response. Clin Neurophysiol. 2007;118(4):869-76. https://doi.org/10.1016/j. clinph.2006.12.015 PMid:17317296

12. Hall JW. ABR: Pediatric clinical application and populations. In: New Handbook for Auditory Evoked Responses. United States: Allyn \& Bacon; 2007. p. 313-41.

13. Cebulla $M$, Shehata-Dieler W. ABR-based newborn hearing screening with MB11 BERAphone ${ }^{\circledR}$ using an optimized chirp for acoustical stimulation. Int J Pediatr Otorhinolaryngol. 2012;76(4):536-43. https://doi.org/10.1016/j.ijporl.2012.01.012 PMid:22310071

14. Chen S, Yang EY, Kwan M, Chang P, Shiao A, Lien C. Infant hearing screening with an automated auditory brainstem response screener and the auditory brainstem response. Acta Paediatr. 1996;85(1):14-8. $\quad$ https://doi.org/10.1111/j.1651-2227.1996. tb13883.x

PMid:8834973 